\title{
Turnover de carbono nos tecidos de frangos de corte em diferentes fases de crescimento
}

\author{
Carbon turnover in poultry tissues at different growth stages
}

\section{Carlos Ducatti ${ }^{{ }^{*}}$ Mariela Akie Okino Mituo ${ }^{\mathrm{I}}$ Juliana Célia Denadai ${ }^{\mathrm{II}}$ Marcela Buosi Martins ${ }^{\mathrm{II}}$ Cibele Regina de Souza-Kruliski ${ }^{\text {I }}$ Vanessa Cristina Pelícia ${ }^{I}$ José Roberto SartoriI}

\section{RESUMO}

Este trabalho objetivou determinar o turnover do carbono no Pectoralis major, quilha, tíbia e fígado de frangos de corte em seus diferentes períodos de crescimento, utilizando a técnica dos isótopos estáveis. Foram utilizados 216 pintos de corte, machos, Cobb. O delineamento experimental foi inteiramente casualizado e consistiu de sete tratamentos com dias de substituição das dietas distintos: $0 ; 7 ; 14 ; 21 ; 28 ; 35 ; 42$ dias de idade. Para mensurar o turnover do carbono nos tecidos em determinado intervalo de tempo, foi utilizado o modelo sigmoidal de regressão de Boltzmann ou função exponencial do tempo. Os valores de meiasvidas foram: 2,$5 ; 2,8 ; 2,9 ; 4,9 ; 5,1 ; 5,5$ e 6,0 dias para músculo peitoral; 2,7; 2,9; 3,1; 4,6; 5,3; 4,1 e 8,0 dias para quilha; 4,4; 3,6; 5,$4 ; 5,8 ; 4,3 ; 5,2$ e 6,3 dias para tíbia e 1,$3 ; 1,9 ; 1,4 ; 1,5 ; 1,9 ; 1,7$ e 2,1 dias para fígado, nos tratamentos T1, T2, T3, T4, T5, T6 e T7, respectivamente. Pode-se concluir que a tíbia possui metabolismo lento e pode indicar o sinal isotópico das dietas iniciais da criação dos frangos de corte; e o fígado, metabolismo rápido, indicado para refletir a dieta próxima da fase de avaliação.

Palavras-chave: diluição isotópica, isótopo ${ }^{13} \mathrm{C}$, meia-vida.

\section{ABSTRACT}

The aim of this study was to evaluate carbon turnover on muscle tissue Pectoralis major, keel, tibia and liver of poultry at different life stages using the carbon stable isotopes technique. 216 male chick lings (Cobb) were used. The trial was conduced in a totally random distribution consisting on seven treatments with distinct days for diet substitution (0, 7, 14, 21, 28, 35, 42 days old). Either Boltzmann sigmoid regression or the exponential time function were used in order to measure the carbon isotopic turnover in a specific period of time. The half-life were: $2.5 ; 2.8$; 2.9; 4.9; $5.1 ; 5.5$ e 6.0 day on muscle tissue; $2.7 ; 2.9 ; 3.1 ; 4.6$; 5.3; 4.1 e 8.0 day on keel; 4.4 ; 3.6; 5.4; 5.8; 4.3 ; 5.2 e 6.3 day on tibia and $1.3 ; 1.9 ; 1.4 ; 1.5 ; 1.9 ; 1.7$ and 2.1 day on liver, for to treatments T1, T2, T3, T4, T5, T6 e T7 respectively. According to the results of this study, it is possible to conclude that the tibia has slowest metabolism and may indicate the isotopic signature of initial diets of poultry culture. The fast metabolism tissue, liver, is appropriated to reflect the diets fed at closer period of evaluation.

Key words: half-life, isotopic dilution, isotope ${ }^{13} \mathrm{C}$.

\section{INTRODUÇÃO}

Os constituintes corporais encontram-se em estado dinâmico, sendo continuamente formados e utilizados para diferentes propósitos. Esse processo é chamado de turnover. As taxas de turnover podem variar entre as diferentes espécies, tecidos, frações bioquímicas e são influenciadas pelo estado fisiológico do animal (KENNEDY \& KROUSE, 1990).

A maioria dos estudos de turnover utilizando as variações naturais do $\delta^{13} \mathrm{C}$ dos alimentos apresenta questões ecológicas, enfocando a velocidade de troca do carbono tecidual a partir da ingestão de alimentos com razões isotópicas distintas. Entretanto, a técnica de isótopos estáveis pode ser útil em estudos de fisiologia e nutrição animal, uma vez que as taxas de substituição do carbono tecidual podem ser influenciadas por fatores ambientais, nutricionais e sanitários (CARRIJO et al., 2000).

A técnica dos isótopos estáveis apresenta potencial de aplicação prática para a rastreabilidade de subprodutos de origem animal na alimentação de

'Centro de Isótopos Estáveis, Instituto de Biociências (IBB), Universidade Estadual Paulista 'Júlio de Mesquita Filho”(UNESP), 18618-970, Botucatu, SP, Brasil. E-mail: ducatti@ibb.unesp.br. *Autor para correspondência.

IIDepartamento de Melhoramento e Nutrição Animal, Faculdade de Medicina Veterinária e Zootecnia (FMVZ), UNESP, Botucatu, SP, Brasil. 
frangos de corte por meio da análise de seus tecidos (CARRIJO et al., 2006).

O conhecimento do tempo de substituição de carbono nos tecidos em função das diferenças fisiológicas durante todas as fases de crescimento dos frangos de corte é de extrema importância, pois, no processo de rastreabilidade de subprodutos de origem animal, tecidos de metabolismo lento podem evidenciar mudanças na dieta na fase inicial, no entanto, tecidos de metabolismo rápido podem indicar troca de dieta na fase final de produção de frangos de corte. Dessa forma, este trabalho objetivou avaliar o turnover do carbono pela substituição de dieta composta predominantemente de grãos do ciclo fotossintético $\mathrm{C}_{4}$ por dieta composta exclusivamente de grãos do ciclo fotossintético $\mathrm{C}_{3}$, no tecido muscular Pectoralis major, quilha, tíbia e fígado, de frangos de corte em seus diferentes períodos de crescimento, utilizando a técnica dos isótopos estáveis.

\section{MATERIAL E MÉTODOS}

A temperatura e a ventilação foram controladas a fim de manter a zona de conforto térmico durante o período de criação, conforme SARTORI et al. (2001)

Foram utilizados 216 pintainhos de corte machos, da linhagem Cobb, com um dia de idade, vacinados no incubatório contra as doenças de Gumboro, Marek, Bouba Aviária e Coccidiose. As aves foram alojadas em 36 gaiolas de arame galvanizado, medindo $0,5 \mathrm{~m}$ de altura, $0,5 \mathrm{~m}$ de largura e $0,6 \mathrm{~m}$ de profundidade, com comedouros individuais tipo calha e bebedouros tipo nipple, sendo que a água e ração foram fornecidas ad libitum. Os pintainhos foram obtidos de matrizes que recebiam dietas compostas predominantemente por grãos de plantas $\mathrm{C}_{4}$ e, ao nascerem, estes possuíam em seus tecidos corporais sinais isotópicos semelhantes a estas dietas, com valores de $\delta^{13} \mathrm{C}=-19,96 \%{ }_{0} \pm 0,15 ;-18,19 \% 0 \pm 0,18$; $-16,59 \%{ }_{0} \pm 0,09$ e $-19,40 \%{ }_{0} \pm 0,15$ para o músculo peitoral, quilha, tíbia e fígado, respectivamente. A fim de manter o sinal isotópico destes pintainhos, até o início do período a ser avaliado, estes receberam dieta composta predominantemente de plantas $\mathrm{C}_{4}$ (Tabela 1 ).

$\mathrm{O}$ delineamento experimental foi inteiramente casualizado, com sete tratamentos avaliados: T1: uso contínuo da dieta $\mathrm{C}_{3}$; $\mathrm{T} 2$ : fornecimento da dieta $\mathrm{C}_{3}$ aos 7 dias; T3: fornecimento da dieta $\mathrm{C}_{3}$ aos 14 dias; T4: fornecimento da dieta $\mathrm{C}_{3}$ aos 21 dias; T5: fornecimento da dieta $\mathrm{C}_{3}$ aos 28 dias; T6: fornecimento da dieta $\mathrm{C}_{3}$ aos 35 dias e T7: fornecimento da dieta $\mathrm{C}_{3}$ aos 42 dias. As exigências nutricionais das aves foram divididas em duas fases: inicial (1 a 21 dias) e crescimento (22 a 56 dias) e adaptadas das recomendações de ROSTAGNO et al. (2005), para diminuir a variação nos sinais isotópicos das dietas (Tabela 1).

Para a coleta das amostras, foram tomadas aleatoriamente quatro aves por tratamento, e sacrificadas por deslocamento da articulação crânio-cervical. Considerando-se cada ave uma repetição, foram colhidas amostras de músculo peitoral, quilha, tíbia e fígado.

As amostras de músculo peitoral, quilha e tíbia foram obtidas segundo metodologia descrita em OLIVEIRA et al. (2010) e o fígado foi retirado totalmente. As coletas foram concentradas nos três primeiros dias de cada tratamento, devido à maior velocidade de troca do carbono no tecido durante essa fase. Para a realização das análises isotópicas no espectrômetro de massas DELTA-S (Finnigan Mat) acoplado ao analisador elementar (EA 1108 CHN), as amostras foram processadas segundo DENADAI et al. (2011).

Os resultados foram expressos em notação $\delta^{13} \mathrm{C}$, em relação ao padrão Peedee Belemnite (PDB), com erro de análise da ordem de $0,2 \%$ e calculado pela equação 1 :

$\delta^{13} \mathrm{C}_{\text {(amostra, padrão) }}=\left[\left(\mathrm{R}_{\text {amostra }} / \mathrm{R}_{\text {padrão }}\right)-1\right] \times 10^{3}$

$\delta^{13} \mathrm{C}=$ enriquecimento da razão ${ }^{13} \mathrm{C} /{ }^{12} \mathrm{C}$ da amostra em relação ao padrão $\mathrm{PDB}$, em partes per mil (\%o). Adimensional; $\mathrm{R}=$ razão isotópica $\left({ }^{13} \mathrm{C} /{ }^{12} \mathrm{C}\right) \mathrm{da}$ amostra e do padrão. Adimensional.

Para mensurar o turnover isotópico do carbono em determinado intervalo de tempo, foi utilizado o modelo sigmoidal de regressão de Boltzmann (Equação 2) ou a função exponencial do tempo expressa (Equação 3), atribuindo-se terminologia isotópica (DUCATTI et al., 2002), por meio o software Origin $^{\circledR} \quad 6.0$ Professional (MICROCAL SOFTWARE, 1999):

$$
\delta^{13} C(t)=\delta^{13} C(f)+\frac{\delta^{13} C(i)-\delta^{13} C(f)}{1+e^{\frac{\left(t-\chi_{0}\right)}{d x}}}
$$

$\delta^{13} \mathrm{C}(\mathrm{i})=$ enriquecimento relativo inicial no tecido; $\delta^{13} \mathrm{C}(\mathrm{f})=$ enriquecimento relativo final no tecido; $\delta^{13} \mathrm{C}(\mathrm{t})=$ enriquecimento relativo no tecido em qualquer tempo; $\chi_{0}=$ ponto de inflexão da sigmoide (meia-vida),em dias; $d x=$ constante de tempo, em dias; $\mathrm{t}=$ tempo experimental, em dias.

$\delta^{13} \mathrm{C}(\mathrm{t})=\delta^{13} \mathrm{C}(\mathrm{f})+\left[\delta^{13} \mathrm{C}(\mathrm{i})-\delta^{13} \mathrm{C}(\mathrm{f})\right] \mathrm{e}^{-\mathrm{kt}}$

Ciência Rural, v.44, n.8, ago, 2014. 
Tabela 1 - Composição percentual, níveis nutricionais calculados e valores isotópicos das dietas experimentais.

\begin{tabular}{|c|c|c|c|c|}
\hline Ingredientes, $\%$ & Inicial $\mathrm{C}_{3}$ & Crescimento $\mathrm{C}_{3}$ & Inicial $\mathrm{C}_{4}$ & Crescimento $\mathrm{C}_{4}$ \\
\hline Milho moído & - & 3,62 & 57,61 & 59,52 \\
\hline Farelo de soja & 35,68 & 27,51 & 36,21 & 28,45 \\
\hline Arroz quirera & 59,34 & 65,00 & - & 5,30 \\
\hline Óleo bruto de soja & - & 0,42 & 2,17 & 3,68 \\
\hline Calcário calcítico & 0,80 & 0,69 & 0,88 & 0,77 \\
\hline Fosfato bicálcico & 2,02 & 1,69 & 1,92 & 1,58 \\
\hline DL-Metionina & 0,23 & 0,16 & 0,21 & 0,14 \\
\hline L-Lisina & 0,21 & 0,16 & 0,25 & 0,20 \\
\hline Suplemento vitamínico e mineral & $0,40^{1}$ & $0,40^{2}$ & $0,40^{1}$ & $0,40^{2}$ \\
\hline Sal comum & 0,35 & 0,35 & 0,35 & 0,35 \\
\hline Caulim & 0,97 & - & - & - \\
\hline \multicolumn{5}{|l|}{ Níveis nutricionais calculados } \\
\hline $\mathrm{EM}, \mathrm{Kcal} \mathrm{kg}^{-1}$ & 2975 & 3150 & 2975 & 3150 \\
\hline $\mathrm{PB}, \%$ & 21,50 & 18,50 & 21,50 & 18,50 \\
\hline $\mathrm{Ca}, \%$ & 0,91 & 0,77 & 0,91 & 0,77 \\
\hline P disp., \% & 0,46 & 0,39 & 0,46 & 0,39 \\
\hline Metionina, $\%$ & 0,58 & 0,48 & 0,54 & 0,43 \\
\hline Metionina + Cistina, $\%$ & 0,88 & 0,73 & 0,88 & 0,73 \\
\hline Lisina, $\%$ & 1,24 & 1,02 & 1,24 & 1,02 \\
\hline \multicolumn{5}{|c|}{ Valores isotópicos médios analisados ${ }^{3}$} \\
\hline$\delta^{13} \mathrm{C}, \%$ & $-28,11 \pm 0,01$ & $-27,59 \pm 0,06$ & $-18,92 \pm 0,10$ & $-18,91 \pm 0,07$ \\
\hline
\end{tabular}

${ }^{1}$ Suplemento vitamínico e mineral da Nutron ${ }^{\circledR}$ para fase inicial por Kg de ração: $\mathrm{Mn}=75 \mathrm{mg} ; \mathrm{Zn}=70 \mathrm{mg} ; \mathrm{Fe}=45 \mathrm{mg} ; \mathrm{Cu}=8 \mathrm{mg} ; \mathrm{I}=0,75 \mathrm{mg}$; $\mathrm{Se}=0,3 \mathrm{mg}$; Vit. $\mathrm{A}=6.720 \mathrm{UIkg}^{-1}$; Vit. D3 = 1.600UI kg ${ }^{-1}$; Vit. $\mathrm{E}=14 \mathrm{mg}$; Vit. K3 =1,44mg; Vit. B1 = 1,75mg; Vit. B2 = 4,8mg; Vit. B6 = 2,496mg; Vit. B12 = 9,6mcg; Ác. Fólico = 0,8mg; Ác. Pantotênico = 12,48mg; Niacina = 33,6mg; Biotina = 0,04mg; Colina = 302,8mg; Coccidiostático $=100 \mathrm{mg}$; Promotor de crescimento $=80 \mathrm{mg} .{ }^{2}$ Suplemento vitamínico e mineral da Nutron ${ }^{\circledR}$ para fase de crescimento por Kg de ração: $\mathrm{Mn}=75 \mathrm{mg} ; \mathrm{Zn}=70 \mathrm{mg} ; \mathrm{Fe}=45 \mathrm{mg} ; \mathrm{Cu}=8 \mathrm{mg} ; \mathrm{I}=0,75 \mathrm{mg} ; \mathrm{Se}=0,3 \mathrm{mg}$; Vit. $\mathrm{A}=5.600 \mathrm{UI} \mathrm{kg}^{-1} ; \mathrm{Vit}$. D3 = 1.200UI kg${ }^{-1}$; Vit. $\mathrm{E}=$ 10mg; Vit. K3 = 1,2mg; Vit. B1 = 1,55mg; Vit. B2 = 4mg; Vit. B6 = 2,08mg; Vit. B12 = 8mcg; Ác. Fólico = 0,65mg; Ác. Pantotênico = 10,4mg; Niacina $=28 \mathrm{mg}$; Colina $=261 \mathrm{mg}$; Coccidiostático $=60 \mathrm{mg}$; Promotor de crescimento $=80 \mathrm{mg}$. ${ }^{3}$ Valores isotópicos médios expressos em $\delta^{13} \mathrm{C}$ relativos ao padrão PeeDee Belemnite $(\mathrm{PDB}),(\mathrm{n}=2)$.

$\delta^{13} \mathrm{C}(\mathrm{t})=$ enriquecimento isotópico do tecido em qualquer tempo $(\mathrm{t}) ; \delta^{13} \mathrm{C}(\mathrm{f})=$ enriquecimento isotópico do tecido no patamar de equilíbrio, ou condição final; $\delta^{13} \mathrm{C}(\mathrm{i})=$ enriquecimento isotópico do tecido, na condição inicial; $\mathrm{k}=$ constante de troca (turnover) em dia ${ }^{-1} ; \mathrm{t}=$ tempo (dias) a partir $\mathrm{da}$ substituição da dieta.

A meia-vida do ${ }^{13} \mathrm{C}$ para os tecidos, na condição de $50 \%$ de troca do carbono, em $\mathrm{t}=\mathrm{T}$, foi calculada pela equação 4 :

$$
\mathrm{T}=\ln 2 / \mathrm{k}
$$

$\mathrm{T}=$ meia-vida, em tempo (dias); $\mathrm{ln}=$ logaritmo niperiano; $\mathrm{k}=$ constante da taxa de turnover no tecido, em dia ${ }^{-1}$.

Os valores do fracionamento isotópico dos tecidos ao final dos períodos dos tratamentos experimentais em relação às dietas foram calculados de acordo com DENIRO \& EPSTEIN (1978), pela equação (5):

$$
\Delta=\delta_{\text {tecido }}-\delta_{\text {dieta }}
$$

$\Delta=$ fator de fracionamento entre o tecido e a dieta, em partes per mil (\%o); $\delta_{\text {tecido }}=$ enriquecimento relativo do tecido em questão, em partes per mil (\%o); $\delta_{\text {dieta }}=$ enriquecimento relativo médio da respectiva dieta, em partes per mil (\%o).

Nos tratamentos T1 e T2, o valor isotópico da dieta para o cálculo foi $\delta_{\text {dieta }}=$ $-28,11 \%$, pois os animais destes tratamentos receberam apenas a dieta inicial. Para o tratamento T3, foi considerada como valor isotópico da dieta a média aritmética das dietas (inicial e final), que foi $\delta_{\text {dieta }}=-27,85 \%$, pois estes animais receberam as duas dietas por um período de sete dias cada. $\mathrm{O}$ fracionamento isotópico dos tratamentos de T4 a T7 foram calculados com base no valor isotópico da dieta final $\left(\delta_{\text {dieta }}=-27,59 \%\right)$.

\section{RESULTADOS E DISCUSSÃO}

Os resultados isotópicos da análise do músculo peitoral, quilha e tíbia do tratamento 
T1 foram explicitados pelo modelo sigmoidal de Boltzmann. Este comportamento pode ser explicado, pois, após o alojamento, os pintainhos nutrem-se do saco vitelino e apresentam baixo consumo de ração, devido ao estresse, causando baixa troca de sinal isotópico nas primeiras 24 horas (Figura 1).

A incorporação do sinal isotópico da dieta $\mathrm{C}_{3}$ começa após este período crítico, indicando o início da deposição de tecido corporal. Segundo RUTZ et al. (2006), é justamente durante a primeira semana de vida que a ave atravessa um dos momentos fisiologicamente mais difíceis, deixando de se alimentar da dieta endógena (fundamentalmente rico em proteínas e lipídios presentes no saco vitelino) e iniciando a alimentação por dieta exógena a base de proteínas, lipídios e carboidratos complexos, estes de difícil digestão pelo trato gastrointestinal, já que nesta fase as aves ainda não apresentam um complexo enzimático completamente desenvolvido.

$\mathrm{O}$ fígado no tratamento $\mathrm{T} 1$ respondeu de forma exponencial. Este fato pode ser consequência da elevada taxa metabólica deste órgão considerado quimicamente reativo (GUYTON \& HALL, 2006).

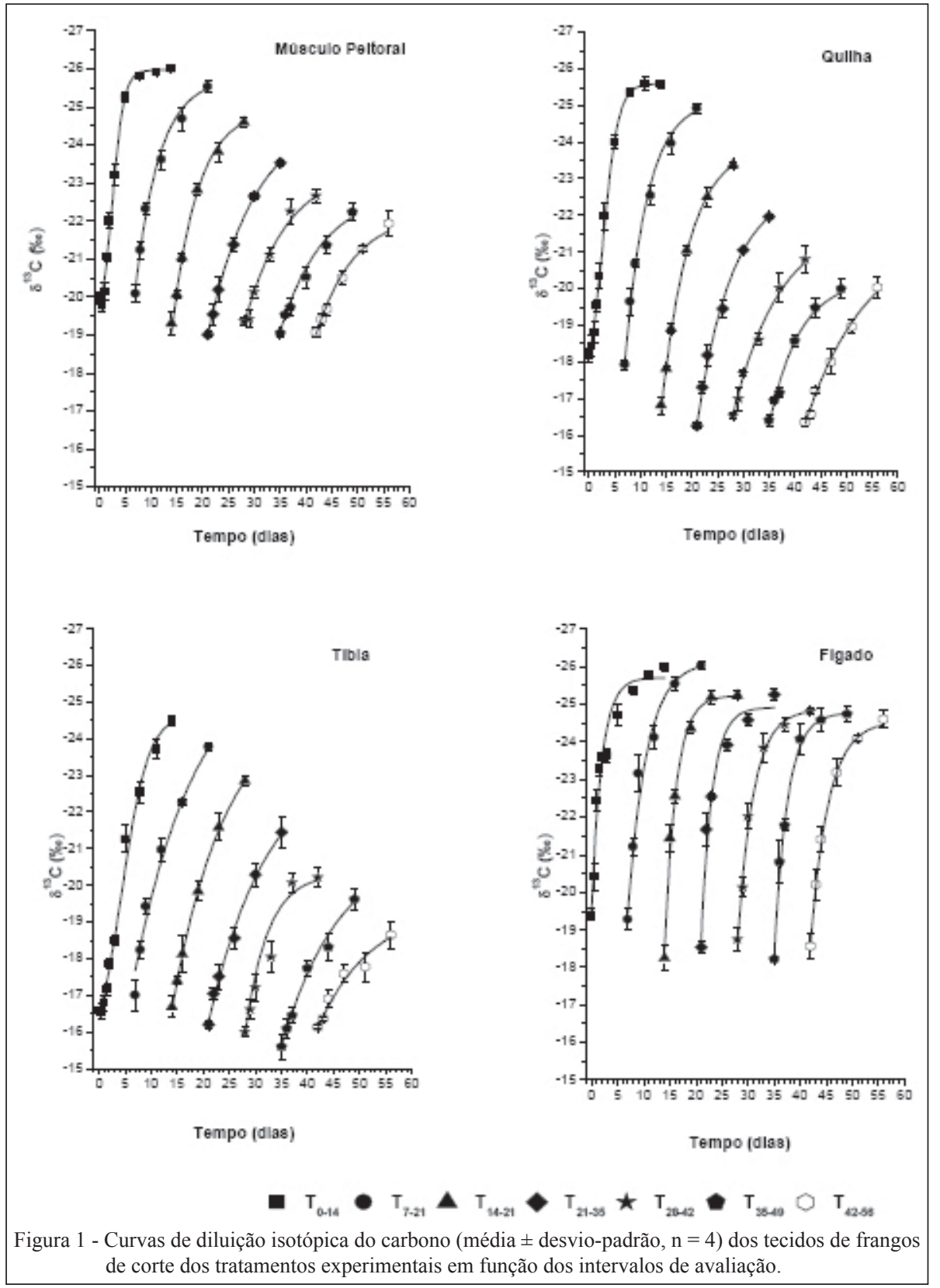

Ciência Rural, v.44, n.8, ago, 2014. 
Os resultados dos demais tratamentos foram explicitados pela função exponencial do tempo, que estão de acordo com o modelo proposto por DUCATTI et al. (2002), quando avaliaram a substituição de carbono tecidual em poedeiras adultas, e também com ZUANON et al. (2006) que afirmaram que o modelo pode ser utilizado para animais em crescimento.

As curvas de diluição isotópica do músculo peitoral e da quilha (Figura 1) indicaram que apenas os tratamentos T1 e T2 atingiram o patamar de equilíbrio isotópico; pela comparação das equações (Tabela 2) e dos fatores de fracionamento (Tabela 3), pode-se verificar que apenas o tratamento T2 se aproximou dos valores do tratamento T1, apesar da curva do tratamento T2 não ter apresentado patamar.

Observando as curvas de diluição isotópica da tíbia (Figura 1), pode-se verificar que apenas o tratamento $\mathrm{T} 1$ chegou próximo do novo patamar de equilíbrio isotópico. Nos outros tratamentos, o tempo de coleta de dados não foi suficiente para que este patamar fosse alcançado. Nas equações (Tabela 2), foi verificado que os valores isotópicos finais foram diferentes entre si. Além disso, pelo cálculo do fator de fracionamento isotópico (Tabela 3), podese observar que, com o aumento da idade inicial de avaliação, houve aumento no fator de fracionamento.
Estes resultados concordam com HAMMOND et al. (1983), que afirmam que o crescimento corporal após o nascimento (idade versus peso corporal) pode ser representado por curva sigmoidal. $\mathrm{O}$ melhor exemplo é o crescimento lento dos músculos, ossos e órgãos vitais durante estágios posteriores de crescimento pós-natal, com concomitante aumento na taxa de deposição de gordura.

A incorporação do carbono da dieta $\mathrm{C}_{3}$ no fígado (Figura 1) ocorreu de forma rápida, de modo que todos os tratamentos atingiram o novo patamar de equilíbrio isotópico e geraram equações semelhantes entre si (Tabela 2). Além disso, os valores de fracionamento isotópico entre o fígado e a dieta (Tabela 3) não sofreram grandes alterações.

Os valores de meia-vida do músculo peitoral, quilha e tíbia (Tabela 3 ) podem ser divididos em dois grupos, de acordo com a fase de crescimento e metabolismo da ave. O primeiro grupo pode ser determinado pelos tratamentos T1, T2 e T3, em que as meias-vidas dos tecidos obtiveram valores semelhantes, indicando rápido crescimento do animal, turnover e meias-vidas curtas semelhantes entre tratamentos, e consequente alta incorporação do carbono. Os demais tratamentos (segundo grupo) apresentaram também meias-vidas semelhantes entre

Tabela 2 - Equações exponenciais das diluições isotópicas em função do tempo do músculo peitoral, da quilha, da tíbia e do fígado.

\begin{tabular}{|c|c|c|}
\hline Tratamentos & Músculo Peitoral & Quilha \\
\hline $\mathrm{T}_{0-14}$ & $\delta^{13} C=-25,96+\frac{6,89}{1+e^{\frac{t-2,54}{1,13}}}$ & $\delta^{13} C=-25,60+\frac{8,71}{1+e^{\frac{t-2,71}{1,50}}}$ \\
\hline $\mathrm{T}_{7-21}$ & $\delta^{13} C=-25,66+5,57 e^{-0,2455(t-7)}$ & $\delta^{13} C=-25,12+7,18 e^{-0,2422(t-7)}$ \\
\hline $\mathrm{T}_{14-28}$ & $\delta^{13} C=-24,78+4,14 e^{-0,2415(t-14)}$ & $\delta^{13} C=-23,70+7,34 e^{-0,2242(t-14)}$ \\
\hline $\mathrm{T}_{21-35}$ & $\delta^{13} C=-24,22+5,27 e^{-0,1417(t-21)}$ & $\delta^{13} C=-22,72+6,43 e^{-0,1502(t-21)}$ \\
\hline $\mathrm{T}_{28-42}$ & $\delta^{13} C=-23,32+4,05 e^{-0,1348(t-28)}$ & $\delta^{13} C=-21,64+5,16 e^{-0,1302(t-28)}$ \\
\hline $\mathrm{T}_{35-49}$ & $\delta^{13} C=-22,74+3,66 e^{-0,1271(t-35)}$ & $\delta^{13} C=-20,39+4,08 e^{-0,1688(t-35)}$ \\
\hline $\mathrm{T}_{42-56}$ & $\delta^{13} C=-22,50+3,45 e^{-0,1163(t-42)}$ & $\delta^{13} C=-21,52+5,21 e^{-0,0868(t-42)}$ \\
\hline Tratamentos & Tíbia & Fígado \\
\hline $\mathrm{T}_{0-14}$ & $\delta^{13} C=-24,66+\frac{9,59}{1+e^{\frac{t-4,4}{2,54}}}$ & $\delta^{13} C=-25,71+6,19 e^{-0,5169 t}$ \\
\hline $\mathrm{T}_{7-21}$ & $\delta^{13} C=-23,96+6,89 e^{-0,1928(t-7)}$ & $\delta^{13} C=-25,89+6,60 e^{-0,3726(t-7)}$ \\
\hline $\mathrm{T}_{14-28}$ & $\delta^{13} C=-24,04+7,44 e^{-0,1295(t-14)}$ & $\delta^{13} C=-25,25+6,95 e^{-0,4998(t-14)}$ \\
\hline $\mathrm{T}_{21-35}$ & $\delta^{13} C=-22,51+6,29 e^{-0,1202(t-21)}$ & $\delta^{13} C=-25,00+6,41 e^{-0,4769(t-21)}$ \\
\hline $\mathrm{T}_{28-42}$ & $\delta^{13} C=-20,88+4,91 e^{-0,1627(t-28)}$ & $\delta^{13} C=-24,84+6,26 e^{-0,3626(t-28)}$ \\
\hline $\mathrm{T}_{35-49}$ & $\delta^{13} C=-20,24+4,72 e^{-0,1336(t-35)}$ & $\delta^{13} C=-24,79+6,57 e^{-0,4053(t-35)}$ \\
\hline $\mathrm{T}_{42-56}$ & $\delta^{13} C=-19,28+3,18 e^{-0,1105(t-42)}$ & $\delta^{13} C=-24,43+5,85 e^{-0,3326(t-42)}$ \\
\hline
\end{tabular}


Tabela 3 - Valores calculados de meias-vidas (dias) e fator de fracionamento isotópico (\%o) entre tecido e dieta dos frangos de corte.

\begin{tabular}{|c|c|c|c|c|}
\hline Tratamentos & Músculo Peitoral & Quilha & Tíbia & Fígado \\
\hline $\mathrm{T}_{0-14}$ & 2,5 & 2,7 & 4,4 & 1,3 \\
\hline $\mathrm{T}_{7-21}$ & 2,8 & 2,9 & 3,6 & 1,9 \\
\hline $\mathrm{T}_{14-28}$ & 2,9 & 3,1 & 5,4 & 1,4 \\
\hline $\mathrm{T}_{21-35}$ & 4,9 & 4,6 & 5,8 & 1,5 \\
\hline $\mathrm{T}_{28-42}$ & 5,1 & 5,3 & 4,3 & 1,9 \\
\hline $\mathrm{T}_{35-49}$ & 5,5 & 4,1 & 5,2 & 1,7 \\
\hline $\mathrm{T}_{42-56}$ & 6,0 & 8,0 & 6,3 & 2,1 \\
\hline $\mathrm{T}_{0-14}$ & 2,11 & 2,52 & $\begin{array}{c}(\Delta)^{*}--- \\
3,60\end{array}$ & 2,11 \\
\hline $\mathrm{T}_{7-21}$ & 2,58 & 3,15 & 4,33 & 2,08 \\
\hline $\mathrm{T}_{14-28}$ & 3,26 & 4,47 & 5,00 & 2,61 \\
\hline $\mathrm{T}_{21-35}$ & 4,06 & 5,63 & 6,14 & 2,33 \\
\hline $\mathrm{T}_{28-42}$ & 4,93 & 7,56 & 7,37 & 2,77 \\
\hline $\mathrm{T}_{35-49}$ & 5,36 & 7,60 & 7,97 & 2,85 \\
\hline $\mathrm{T}_{42-56}$ & 5,66 & 7,55 & 8,94 & 2,99 \\
\hline
\end{tabular}

$* \Delta=\delta_{\text {tecido }}-\delta_{\text {dieta }}$

si, indicando crescimento desacelerado, turnover mais lento e menor incorporação de carbono.

Os valores de meia-vida do fígado de todos os tratamentos mostraram-se semelhantes entre si, indicando pouca variação de turnover, que, mesmo com a ave e seus tecidos crescendo, o metabolismo do fígado mostrou-se tão intenso em qualquer fase da vida, seja a ave jovem ou mais adulta.

As meias-vidas dos tecidos estudados, em geral, aumentaram de acordo com o avanço da idade de avaliação. A tíbia foi o tecido que apresentou maior valor de meia-vida quando comparada aos outros tecidos, indicando lenta incorporação de carbono. Os menores valores de meia-vida dos tratamentos experimentais foram encontrados no fígado, sugerindo rápida incorporação do carbono. $\mathrm{O}$ músculo peitoral e a quilha apresentaram valores de meia-vida próximos entre si e intermediário aos anteriores.

Analisando os fatores de fracionamento contidos na tabela 3 , foi possível observar que, com o aumento da idade inicial de avaliação, aumentou-se o valor do fator de fracionamento no músculo peitoral, quilha e tíbia, e apenas os valores de fracionamento do fígado não sofreram grande variação, sugerindo que o tempo de avaliação a partir do tratamento T2, ou seja, em pintainhos de sete dias de idade ou mais, não foi suficiente para que estes tecidos alcançassem o novo patamar de equilíbrio isotópico. Por outro lado, no fígado, mostrou-se suficiente. Esta constatação sugere que novos estudos sejam realizados, aumentando o tempo de avaliação para que os valores de meiasvidas possam ser reafirmados ou não.

\section{CONCLUSÃO}

A tíbia pode ser considerada um tecido de metabolismo lento, pois apresenta maior tempo de meia-vida e turnover lento, o que pode refletir o sinal isotópico das dietas iniciais da criação dos frangos de corte. O fígado pode ser considerado tecido de metabolismo rápido, pois apresenta turnover mais rápido, indicado para refletir a dieta próxima da fase de avaliação.

\section{AGRADECIMENTOS}

Os autores agradecem à Fundação de Amparo à Pesquisa do estado de São Paulo (FAPESP) pelo apoio financeiro recebido (auxílio financeiro processo $n^{\circ}: 2007 / 59451-0$ e bolsa de mestrado do segundo autor processo $\mathrm{n}^{\circ}$ : 2006/59368-3).

\section{COMITÊ DE ÉTICA E BIOSSEGURANÇA}

O protocolo de experimentação animal está de acordo com CEUA e foi aprovado pelo comitê de ética no uso de animais, pelo protocolo 119/2006-CEUA.

\section{REFERÊNCIAS}

CARRIJO, A.S. et al. Avaliação do metabolismo nutricional em poedeiras pela técnica dos isótopos estáveis do carbono $\left({ }^{13} \mathrm{C} /{ }^{12} \mathrm{C}\right)$. Revista Brasileira de Ciência Avícola, Campinas, v.2, p.209218, 2000. Disponível em: <http://dx.doi.org/10.1590/S1516635X2000000300003>. Acesso em: 20 nov. 2009. doi: 10.1590/ S1516-635X2000000300003.

CARRIJO, A.S. et al. Traceability of bovine meat and bone meal in poultry by stable isotope analysis. Revista Brasileira de Ciência Avícola, Campinas, v.8, p.63-68, 2006. Disponível em: <http:// 
dx.doi.org/10.1590/S1516-635X2006000100010>. Acesso em: 17 maio 2010. doi: 10.1590/S1516-635X2006000100010.

DENADAI, J.C. et al. Rastreabilidade da farinha de carne e ossos bovinos em ovos de poedeiras comerciais pela técnica dos isótopos estáveis do carbono e nitrogênio. Revista Brasileira de Zootecnia, Brasília, v.40, n.12, p.2760-2766, 2011. Disponível em: <http:// dx.doi.org/10.1590/S1516-35982011001200021>. Acesso em: 02 set. 2010 doi: 10.1590/S1516-35982011001200021.

DENIRO, M.J.; EPSTEIN, S. Influence of diet on the distribution of carbon isotopes in animals. Geochimica et Cosmochimica Acta, London, v.42, p.495-506, 1978. Disponível em: <http:// elibrary.unm.edu/sora/Condor/files/issues/v094n01/p0181-p0188. pdf>. Acesso em: 17 nov. 2009.

DUCATTI, C. et al. Modelo teórico e experimental da reciclagem do carbono-13 em tecidos de mamíferos e aves. Scientia Agrícola, Piracicaba, v.59, n.1, p.29-33, 2002. Disponível em: <http:// dx.doi.org/10.1590/S0103-90162002000100003>. Acesso em: 07 out. 2010. doi: 10.1590/S0103-9016200200010003.

GUYTON, A.C.; HALL, J.E. O fígado como um órgão . In Tratado de fisiologia médica. 11.ed. Rio de Janeiro: Elsevier, 2006. p.859-864

HAMMOND, J. et al. Hammond's farm animals. London: Edward Arnold, 1983. 305p.

KENNEDY, B.V.; KROUSE, H.R. Isotope fractionation by plants and animals: implications for nutrition research. Canadian Journal Physiology and Pharmacology, Ottawa, v.68, p.960972, 1990. Disponível em: <http://dx.doi.org/10.1139/y90-146. Acesso em: 25 nov. 2009>. doi: 10.1139/y90-146.
MICROCAL SOFTWARE INC. Microcal Software Origin ${ }^{\circledR}$ 6.0 Professional. Origin data analysis and technical graphics. Northampton (MS), 1999. 774p.

OLIVEIRA, R.P. et al. Traceability of poultry offal meal in broiler feeding using isotopic analysis $\left(\delta^{13} \mathrm{C}\right.$ and $\left.\delta^{15} \mathrm{~N}\right)$ of different tissues. Revista Brasileira de Ciência Avícola / Brazilian Journal of Poultry Science, Campinas, v.12, p.13-20, 2010. Disponível em: $<$ http://dx.doi.org/10.1590/S1516-635X2010000100002>. Acesso em: 02 set. 2010. doi: 10.1590/S1516-635X2010000100002.

ROSTAGNO, H.S. et al. Tabelas brasileiras para aves e suínos: composição de alimentos e exigências nutricionais. Viçosa: UFV, 2005. $252 \mathrm{p}$

RUTZ, F. et al. Cuidados críticos na nutrição inicial de aves: alternativas para melhorar o desempenho e o papel essencial dos nucleotídeos. Anais Brasil-Sul Avicultura. 2006. Disponível: $<$ http://www.cnpsa.embrapa.br/down.php?tipo=poblicacoesecod publicacao $=770>$. Acesso em: 21 fev. 2009.

SARTORI, J.R. et al. Efeito da temperatura ambiente e da restrição alimentar sobre o desempenho e a composição de fibras musculares esqueléticas de frangos de corte. Revista Brasileira de Zootecnia / Brazilian Journal of Animal Science, Brasília, v.30, p.17791790, 2001. Disponível em: <http://dx.doi.org/10.1590/S151635982001000700016>. Acesso em: 24 jan. 2014. doi: 10.1590/ S1516-35982001000700016.

ZUANON, J.A.S. et al. Muscle $\delta^{13} \mathrm{C}$ change in Nile tilapia (Oreochromis niloticus): Effects of growth and carbon turnover. Comparative Biochemistry and Physiology, Part B, v.145, p.1001-107, 2006. Disponível em: <http://dx.doi.org/10.1016/j. cbpb.2006.06.009>. Acesso em: 07 out. 2010. doi: 10.1016/j. cbpb.2006.06.009. 